\title{
Egg clutch dehydration induces early hatching in red-eyed treefrogs, Agalychnis callidryas
}

\author{
María José Salica ${ }^{\text {Corresp.., }}{ }^{1}$, James R Vonesh ${ }^{2}$, Karen M Warkentin ${ }^{3,4}$ \\ ${ }^{1}$ CONICET, Instituto de Ecorregiones Andinas (INECOA), Universidad Nacional de Jujuy, San Salvador de Jujuy, Argentina \\ 2 Department of Biology, Virginia Commonwealth University, Richmond, VA, United States \\ 3 Department of Biology, Boston University, Boston, MA, USA \\ 4 Smithsonian Tropical Research Institute, Panamá, República de Panamá \\ Corresponding Author: María José Salica \\ Email address: mjsalica@gmail.com
}

Terrestrial eggs have evolved repeatedly in tropical anurans exposing embryos to the new threat of dehydration. Red-eyed treefrogs, Agalychnis callidryas, lay eggs on plants over water. Maternally provided water allows shaded eggs in humid sites to develop to hatching without rainfall, but unshaded eggs and those in less humid sites can die from dehydration. Hatching responses of amphibian eggs to dry conditions are known from two lineages with independent origins of terrestrial eggs. Here, we experimentally tested for dehydration-induced early hatching in another lineage (Agalychnis callidryas, Phyllomedusidae), representing a third independent origin of terrestrial eggs. We also investigated how dehydration affected egg and clutch structure, and egg mortality. We collected clutches from a pond in Gamboa, Panama, and randomly allocated them to wet or dry treatments at age 1 day. Embryos hatched earlier from dry clutches than from wet clutches, accelerating hatching by $\sim 11 \%$. Clutch thickness and egg diameter were affected by dehydration, diverging between treatments over time. Meanwhile, mortality in dry clutches was six-fold higher than in control clutches. With this study, early hatching responses to escape mortality from egg dehydration are now known from three anuran lineages with independent origins of terrestrial eggs, suggesting they may be widespread. Further studies are needed to understand how terrestrial amphibian eggs can respond to, or will be affected by, rapid changes in climate over the next decades. 
1 Egg clutch dehydration induces early hatching in red-eyed treefrogs, Agalychnis callidryas

2

3 María José Salica ${ }^{1}$, James R. Vonesh ${ }^{2}$ and Karen M. Warkentin ${ }^{3,4}$

4

$5{ }^{1}$ Instituto de Ecorregiones Andinas (INECOA), Universidad Nacional de Jujuy - CONICET, San

6 Salvador de Jujuy, Jujuy, Argentina

$7 \quad 2$ Department of Biology, Virginia Commonwealth University, Richmond, VA, USA

$8 \quad{ }^{3}$ Department of Biology, Boston University, Boston, MA, 02215, USA

9 S Smithsonian Tropical Research Institute, Panamá, República de Panamá

11 Corresponding Author:

12 María José Salica ${ }^{1}$

13 Gorriti 237, San Salvador de Jujuy, Jujuy, 4600, Argentina

15 Email address: mjsalica@gmail.com 


\section{Abstract}

25

Terrestrial eggs have evolved repeatedly in tropical anurans exposing embryos to the new threat of dehydration. Red-eyed treefrogs, Agalychnis callidryas, lay eggs on plants over water. Maternally provided water allows shaded eggs in humid sites to develop to hatching without rainfall, but unshaded eggs and those in less humid sites can die from dehydration. Hatching responses of amphibian eggs to dry conditions are known from two lineages with independent origins of terrestrial eggs. Here, we experimentally tested for dehydration-induced early hatching in another lineage (Agalychnis callidryas, Phyllomedusidae), representing a third independent origin of terrestrial eggs. We also investigated how dehydration affected egg and clutch structure, and egg mortality. We collected clutches from a pond in Gamboa, Panama, and randomly allocated them to wet or dry treatments at age 1 day. Embryos hatched earlier from dry clutches than from wet clutches, accelerating hatching by $\sim 11 \%$. Clutch thickness and egg diameter were affected by dehydration, diverging between treatments over time. Meanwhile, mortality in dry clutches was six-fold higher than in control clutches. With this study, early hatching responses to escape mortality from egg dehydration are now known from three anuran lineages with independent origins of terrestrial eggs, suggesting they may be widespread. Further studies are needed to understand how terrestrial amphibian eggs can respond to, or will be affected by, rapid changes in climate over the next decades.

Key words: climate change; hatching plasticity; Panama; Phyllomedusidae; tropical wet forest. 


\section{INTRODUCTION}

Terrestrial eggs have evolved repeatedly in many species of teleost fishes and amphibians

49 (Martin \& Carter, 2013). In tropical anurans, Gomez-Mestre, Pyron \& Wiens (2012) found 48

50 independent origins of terrestrial reproduction. The evolution of terrestrial breeding may be

51 driven by the risk of aquatic predation in early life stages (Duellman \& Trueb, 1986; Touchon,

52 2012). However, nonaquatic reproduction also entails risks. Terrestrial eggs are exposed to

53 different threats than those affecting aquatic eggs, including terrestrial predators (Warkentin,

54 1995, 2000), pathogens (Warkentin, Currie \& Rehner, 2001), and the novel threat of dehydration

55 (Mitchell, 2002, Touchon \& Warkentin, 2009). The risk of egg dehydration most strongly affects

56 species without parental care, and this threat could be exacerbated by climate change (Donnelly

57 \& Crump, 1998). As well as temperature, rainfall patterns are changing in the tropics.

58 Specifically, even if overall rainfall remains similar, in the Neotropics rainfall events are

59 becoming less frequent, resulting in an increase in dry spells during the rainy season (Hulme \&

60 Viner, 1998, Christensen et al., 2007, Allan \& Soden, 2008). Therefore, it is important to

61 understand the potential responses of vulnerable life stages to such climate variations.

62 Environmentally cued variation in hatching time is widespread in many taxa (Warkentin,

63 2011a) and serves as an important defense mechanism against egg-stage risks. Environmentally

64 cued hatching $(\mathrm{ECH})$ is well documented in anurans (Warkentin, 2011b); much of this research

65 addresses biotic threats to eggs and larvae, and a substantial subset addresses responses of

66 embryos to hypoxia. The terrestrial eggs of red-eyed treefrogs, Agalychnis callidryas, one of the

67 most studied species, hatch early in response to multiple environmental threats, including

68 predator attack (snakes, Warkentin, 1995; wasps, Warkentin, 2000), fungal infection (Warkentin,

69 Currie \& Rehner, 2001) and flooding, which can kill embryos too young to hatch (Warkentin, 
70 2002). Embryos presumably use some of the same mechanisms to respond to these different

71 risks. For instance, all responses require a means to exit from the egg and the ability to regulate

72 expression of this process (Cohen, Seid \& Warkentin, 2016). Nonetheless, different types of

73 threat provide very different types of cues. Their detection requires different sensors, and

74 assessing different risks may require different cognitive mechanisms. Thus, embryos that

75 respond to one threat, using one type of cue, may be insensitive to other cues and unresponsive

76 to other threats.

77 Only a few studies of ECH have examined how amphibian eggs respond to drying

78 conditions (Warkentin, 2011b); thus, it is unclear how widespread hatching responses to egg

79 dehydration might be. To date, such responses are known from two lineages with independent

80 origins of terrestrial eggs deposited on vegetation above water in rainforest environments. In the

81 treefrog Dendropsophus ebraccatus (Hylidae: Dendropsophinae), eggs exposed to dehydration

82 hatch earlier and more synchronously than well-hydrated clutches (Touchon \& Warkentin, 2010,

83 Touchon, Urbina \& Warkentin, 2011). In the glassfrog Hyalinobatrachium fleischmanni

84 (Centrolenidae: Hyalinobatrachinae) fathers hydrate their developing embryos during dry

85 weather. When the caring parent is removed, increasing risk of egg dehydration, the embryos

86 also respond by hatching earlier and more synchronously (Delia, Ramírez-Bautista \& Summers,

87 2014). Here, we tested for dehydration-induced early hatching in another lineage (Agalychnis

88 callidryas, Phyllomedusidae), representing a third independent origin of terrestrial eggs. We also

89 investigated how dehydration affected egg and clutch structure, and egg mortality. 


\section{MATERIALS \& METHODS}

\section{Study system}

95

96

\section{Experimental Design}

11524 July 2011 from the Experimental Pond in Gamboa, Panama (907'15" N, 7942'14" W). All 
116 clutches were collected with the leaves on which they were laid, mounted on plastic cards for

117 support and attached to the sides of plastic cups in a vertical orientation. Each cup contained

118 aged tap water to catch hatched tadpoles. Eggs in each clutch were counted, and any dead or

119 undeveloped eggs (possibly unfertilized) were noted. Clutches were randomly allocated to a wet

120 treatment or a dry treatment starting at age 1 day. Wet clutches were heavily sprayed with aged

121 tap water multiple times daily, taking care not to overspray onto dry clutches. Dry clutches were

122 unsprayed or minimally sprayed in some cases where eggs were dying from dehydration.

123 Clutches were located on the same table in a laboratory with a mean temperature of $26.8^{\circ} \mathrm{C}$

124 (range: $25.5-28.5^{\circ} \mathrm{C}$ ), and mean humidity of $82.4 \%$ (range: $78-88 \%$ ); nearby ponds under

125 rainforest canopy cover are usually slightly cooler and more humid. Clutches were maintained on

126 a 12:12 light: dark photoperiod, based on local sunrise/sunset times. All clutches were checked

127 for hatching at least 5 times daily. Clutches were photographed daily with a ruler for egg size

128 measurements, from age 1 to 4 days. At each age, for each clutch, we measured two orthogonal

129 diameters for each of 10 eggs from the photographs, using ImageJ (NIH); for analysis, we used

130 the average of the two diameters. We also measured the thickness of each clutch when it entered

131 the experiment at 1 day old and after two days in the treatments, at 3 days old, by inserting a fine

132 probe orthogonally through the thickest part of the clutch, between eggs, to the leaf surface. This

133 measurement included both eggs and associated jelly thickness.

\section{Statistical Analysis}

135 Analyses were conducted using generalized linear models followed by likelihood ratio or

$136 F$ tests implemented using R v. 3.3.1 (2016-06-21; R Development Core Team 2011). We used

137 logistic regression with binomial errors to test whether the hydration treatment altered the

138 proportion of embryos that survived to hatching. As we focused on embryonic mortality from 
139 desiccation, this analysis excluded embryos that showed no initial development (e.g., presumed

140 unfertilized). We used linear models with normally distributed errors to test for the independent

141 and interactive effects of the hydration treatment and clutch size on time to hatching (h) and of

142 hydration treatment and days post-oviposition (dpo) on egg diameter (mm) and clutch thickness $143(\mathrm{~mm})$.

\section{RESULTS}

Mean survival was significantly lower in clutches from the dry treatment compared to the wet treatment $\left(X^{2}=6.86, \mathrm{df}=1,28, \mathrm{P}=0.009\right.$, dispersion parameter $=15.2$; Fig. 1$)$. Embryonic mortality averaged $24.0 \pm 0.9 \%$ (mean $\pm \mathrm{SE}$, here and throughout) the dry treatment compared to only $4.0 \pm 0.1 \%$ in the wet treatment. Mortality in the dry treatment was also more variable, ranging from zero to $100 \%$. Desiccation mortality occurred early in development; embryos that achieved hatching competence prior to desiccation were able to hatch and escape further drying. of hatching, 2) half of the clutch hatched, and 3) completed hatching. Initiation of hatching depended only on hydration treatment (hydration: $F_{1,24}=9.76, P<0.01$, clutch size: $F_{1,24}=$ 2.04, $P=0.16$, hydration x clutch size: $F_{1,24}=0.08, P=0.8$ ). Embryos from the dry treatments started hatching $10.73 \pm 3.4 \mathrm{~h}$ earlier than the wet treatment (Fig. 2). Time for half of the embryos to hatch depended on both hydration and clutch size (hydration: $F_{1,24}=14.1, P<0.001$, clutch size: $F_{1,24}=6.05, P=0.02$, hydration x clutch size: $F_{1,24}=0.08, P=0.78$ ). Wet clutches reached the $50 \%$ hatch point $16.3 \pm 10.3 \mathrm{~h}$ later than dry clutches and each additional egg in a

160 clutch increased time to half hatch by $0.29 \pm 0.14 \mathrm{~h}$. Time to hatch completely was similarly

161 dependent on hydration and clutch size (hydration: $F_{1,24}=12.7, P=0.0015$, clutch size $F_{1,24}=$ 
$1625.64, P=0.026$, hydration $\mathrm{x}$ clutch size interaction: $\left.F_{1,26}=0.34, P=0.57\right)$. Wet clutches

163 finished hatching $19.9 \pm 11.1 \mathrm{~h}$ later than dry clutches and each additional egg increased time to

164 complete hatching by $0.33 \pm 0.15 \mathrm{~h}$. In both treatments, hatching was gradual and asynchronous,

165 but the entire hatching curve was earlier in the dry treatment (Fig. 3).

166 Mean egg diameter was a function of the interaction between hydration and days post-

167 oviposition (hydration: $X^{2}=33.93, \mathrm{df}=1, P<0.001$; dpo: $X^{2}=12.26, \mathrm{df}=1, P=0.0004$;

168 hydration $\mathrm{x}$ dpo: $X^{2}=15.91, \mathrm{df}=1, P<0.001$, Fig 4). Initially, in both dry and wet clutches, egg

169 diameters increased due to absorption of water from the egg jelly into the perivitelline space;

170 however, wet eggs swelled more rapidly. Eggs in wet clutches continued to swell, then stabilized

171 in diameter at age 3 days. By contrast, from 2 days eggs in dry clutches shrank, with the

172 difference between treatments increasing over time.

173 Mean clutch thickness also was a function of the interaction between hydration and days

174 post-oviposition (hydration: $X^{2}=3.12, \mathrm{df}=1, P=0.077$; dpo: $X^{2}=0.48, \mathrm{df}=1, \mathrm{P}=0.49$;

175 hydration $x$ dpo: $X^{2}=6.05, \mathrm{df}=1, P=0.014$, Fig 5). At the beginning of the experiment, at age 1

176 day, there was no difference in thickness between clutches assigned to different treatments (dry:

$1777.03 \pm 1.70 \mathrm{~mm}$, wet: $6.73 \pm 1.53 \mathrm{~mm}$ ). However, two days later wet clutches were much thicker

178 than dry clutches (dry: $5.67 \pm 1.63 \mathrm{~mm}$, wet: $7.50 \pm 1.84 \mathrm{~mm})$.

179

180 DISCUSSION

181 Our results show that red-eyed treefrogs can accelerate hatching when exposed to the

182 gradual threat of dehydration over embryonic development. In this study, the acceleration in

183 hatching timing (11\%) was less than that reported for other frogs (Dendrosophus ebraccatus:

184 17\%, Touchon \& Warkentin 2010; Hyalinobatrachium fleishmanni: 59\%, Delia, Ramírez- 
185 Bautista \& Summers, 2014). It may be that, compared with those species, $A$. callidryas has a

186 relatively limited capacity to accelerate hatching under the threat of drying. Indeed, based on

187 field monitoring of eggs, both $D$. ebraccatus and H. fleishmanni both appear at higher risk of

188 mortality from dehydration than does A. callidryas. Dehydration led to $98 \%$ mortality in

189 terrestrial eggs of $D$. ebraccatus exposed to lack of rainfall during the first $48 \mathrm{~h}$ post-oviposition

190 (Touchon \& Warkentin, 2009). Similarly, in male removal experiments generating "orphan"

191 clutches of $H$. fleishmanni, 78\% of total mortality was due to dehydration (Delia, Ramírez-

192 Bautista \& Summer, 2013). Alternatively, because the mortality imposed by our drying treatment

193 was moderate (24\%), compared with the possible risk of mortality under more extreme weather

194 conditions, it may not have tested the limits of $A$. callidryas capacity to accelerate hatching.

195 The hatching pattern of drying clutches - accelerated but gradual hatching, over a period

196 of days - was very similar to the hatching pattern of clutches infected by a pathogenic fungus

197 which caused about $40 \%$ mortality and $17 \%$ acceleration of hatching (Warkentin, Currie \&

198 Rehner, 2001, Warkentin, 2011b). Both fungus and dehydration are chronic threats, that affect

199 egg clutches gradually and potentially provide cues over extended periods of development.

200 However, what those cues are, or how embryos detect them, is in both cases unknown. Red-eyed

201 treefrog embryos use physical disturbance or vibrations to assess danger in predator attacks

202 (Warkentin, 2005) and respond by hatching very rapidly, within seconds (Cohen, Seid \&

203 Warkentin, 2016; Warkentin et al., 2007). They also use hypoxia as a cue to hatch from eggs that

204 are flooded, responding to submergence in minutes (Warkentin, 2002). Like fungus infection,

205 dehydration does not move eggs, and neither threat has a sudden, acute onset. Either vibrational

206 cues or another sudden change in clutch conditions may be necessary to induce rapid or

207 synchronous hatching. 
Both clutch thickness and egg diameter were affected by dehydration, diverging between

209 treatments over time. Dehydration began to affect these variables from age 3 days, when both

210 clutch thickness and egg diameter decreased in dry treatment eggs. Our results suggest that

211 during early developmental stages water moves from the jelly layers into the perivitelline space,

212 enlarging the eggs (Salthe, 1965), as diameter of the vitelline chamber increased even in the dry

213 treatment. Later in embryonic development (from 3 days), after available water from jelly layers

214 has been absorbed, the eggs can absorb additional water from external sources, such as rainfall.

215 Without external sources of water, egg diameter then begins to decrease, constricting the

216 perivitelline space. Egg diameter of terrestrial breeding frogs usually decreases when they are

217 exposed to dry conditions (e.g. Kurixalus eiffinger, Kam, Yen \& Hsu, 1998a; Bryobatrachus

218 nimbus, Mitchell, 2002), due to the semipermeable nature of their vitelline membrane (Salthe, 219 1965).

With this study, early hatching responses to escape mortality from egg dehydration are now known from three anuran lineages with independent origins of terrestrial eggs (Hylidae: Dendropsophinae; Centrolenidae; Phyllomedusidae). Other responses to, and effects of, dehydration on terrestrial frog eggs have been explored in other lineages. For example, Kam,

224 Yen \& Hsu (1998a) found the opposite response in Kurixalus eiffinger (Rhacophoridae:

225 Rhacophorinae); well-hydrated eggs hatched earlier than drier eggs. In this species, accelerating 226 the time of hatching under wetter conditions has a clear adaptive significance. Tadpoles of $K$. 227 eiffinger are oophagous. Females lay their first batch of trophic eggs before all the fertilized eggs 228 have hatched, then return eight days later to feed the tadpoles again (Kam et al. 1998b). Tadpoles 229 that hatch earlier obtain more trophic eggs, grow faster and reach metamorphosis earlier. Other 230 studies have been conducted on terrestrial anuran embryos with a similar approach. Most of this 
231 research has focused on effects of different moisture conditions on phenotypic traits (Taigen,

232 Pough \& Stewart, 1984; Bradford \& Seymour, 1988; Seymour, Geiser \& Bradford, 1991a,

233 1991b; Kam, Yen \& Hsu, 1998a, Mitchell, 2002). Anuran embryos exposed to dry conditions

234 grow more slowly (Pseudophryne bibroni, Bradford \& Seymour, 1988), have lower hatching

235 success (e.g. Kurixalus eiffingeri, Kam, Yen \& Hsu, 1998a; Bryobatrachus nimbus, Mitchell,

236 2002), produce smaller hatchlings (e.g. Eleutherodactylus coqui, Taigen, Pough \& Stewart,

237 1984; Kam, Yen \& Hsu, 1998a; Mitchell, 2002) and generate stunted and asymmetric

238 morphologies at hatching (Mitchell, 2002). In A. callidryas, early-induced hatchlings are

239 generally smaller and less developed than full term hatchlings (Warkentin 1995, 1999; Gomez-

240 Mestre et al. 2008). Such differences, however, appear simply to be caused by differences in the

241 period of embryonic development, not by differences in embryonic developmental trajectories,

242 and there is no evidence to date that hatching plasticity in this species occurs by altering the rate

243 of embryo development (Warkentin, 2011a). Nonetheless, in this study we did not collect the

244 detailed morphological data that would be necessary to test for subtle effects of drying on

245 development rate.

246 The anuran lineages now demonstrated to hatch early in response to drying vary in their

247 degree of egg and clutch adaptation to terrestrial development. Dendropsophus ebraccatus egg

248 size and clutch morphology are much like those of aquatic breeding congeners; they appear not

249 to be strongly adapted to terrestrial development, and indeed can also develop aquatically

250 (Touchon \& Warkentin, 2008). In contrast, phyllomedusids have a long (34 to 50 million years)

251 evolutionary history of terrestrial eggs (Gomez-Mestre, Pyron \& Wiens, 2012) and A. callidryas

252 eggs do not survive prolonged submergence (Pyburn, 1970). Considering that these highly

253 adapted terrestrial eggs, which typically do not suffer high dehydration mortality, can show 
254 adaptive plastic responses to reduce mortality from this occasional threat, drying-induced early

255 hatching may be a more general, broadly distributed phenomenon.

256 The risk of dehydration as a source of mortality for terrestrial-breeding frogs is

257 particularly important in the context of global climate change. Local changes in weather and

258 climate can affect the hydration of terrestrial embryos. In D. ebraccatus living in sympatry with

259 A. callidryas, the survival of terrestrial eggs is affected both directly and indirectly by the

260 amount of rainfall (Touchon \& Warkentin, 2009). Directly, rain hydrates eggs and prevents

261 mortality from drying. Indirectly, because the jelly surrounding eggs swells with hydration, rain

262 decreases the risk of predation; dehydrated eggs are more susceptible to predation by ants and

263 wasps. In Phyllomedusa hypochondrialis, which normally wraps its eggs in leaves, the mortality

264 of embryos exposed directly to the air decreased during rainy periods (Pyburn, 1980). The

265 tropics, where the highest biodiversity of amphibians is concentrated, are expected to become

266 warmer and drier, and many tropical anuran lineages have evolved terrestrial eggs. Therefore, to

267 understand how these terrestrial eggs can respond to, or will be affected by, rapid changes in

268 climate over the next decades is relevant for conservation planning.

269 ACKNOWLEDGEMENTS

270 This paper is dedicated to the memory of Monique Halloy, advisor to MJS, with gratitude

271 for her support both personally and in herpetological research. We thank J. Charbonnier, R.

272 Jimenez, S. Abinette, S. Bouchard, K. Cohen and M. Leavy for assistance, and the editor and

273 reviewer for comments and suggestions which improved the manuscript. This research was

274 conducted under permit SC/A-13-11 from the Panama Autoridad Nacional del Ambiente and

275 IACUC approval 100625-1008-15 from the Smithsonian Tropical Research Institute (STRI). 


\section{REFERENCES}

278 Allan RP, Soden BJ. 2008. Atmospheric warming and the amplification of precipitation

279 extremes. Science 321: 148-1484

280 Bradford DF, Seymour RS. 1988. Influence of water potential on growth and survival of the

281 embryo, and gas conductance of the egg, in a terrestrial breeding frog, Pseudophryne bibroni.

282 Physiological Zoology. 61: 470-474

283 Christensen, JH, Hewitson B, Busuioc A, Chen A, Gao X, Held I, Jones R, Kolli RK, Kwon WT,

284 Laprise R, Rueda VM, Mearns L, Menéndez CG, Räisänen J, Rinke A, Sarr A, Whetton P. 2007.

285 Regional climate projections. In: Solomon S, Qin D, Manning M, Chen Z, Marquis M, Averyt

286 KB, Tignor M, Miller HL, eds. Climate change 2007: The physical science basis. Contribution

287 of working group I to the fourth assessment report of the intergovernmental panel on climate

288 change. Cambridge: Cambridge University Press, 847-940

289 Cohen KL, Seid MA, Warkentin KM. 2016. How embryos escape from danger: the mechanism

290 of rapid, plastic hatching in red-eyed treefrogs. The Journal of Experimental Biology 219: 1875-

$291 \quad 1883$

292 Delia JR, Ramírez-Bautista A, Summers K. 2013. Parents adjust care in response to weather

293 conditions and egg dehydration in a Neotropical glassfrog. Behavioral Ecology and Sociobiology

294 67: 557-569

295 Delia JR, Ramírez-Bautista A, Summers K. 2014. Glassfrog embryos hatch early after parental

296 desertion. Proceedings of the Royal Society. Biological sciences 281: 20133237

297 Donnelly MA, Crump ML. 1998. Potential effects of climate change on two neotropical

298 amphibian assemblages. In: Markham A, ed. Potential Impacts of Climate Change on Tropical

299 Forest Ecosystems. Netherlands: Springer, 401-421 
300 Duellman WE, Trueb L. 1986. Biology of Amphibians. Baltimore: JHU Press

301 Duellman WE, Marion AB, Hedges SB. 2016. Phylogenetics, classification, and biogeography of

302 the treefrogs (Amphibia: Anura: Arboranae). Zootaxa 4104: 1-109

303 Faivovich J, Haddad CFB, Baêta D, Jungfer KH, Álvares GFR, Brandão RA, Sheil CA,

304 Barrientos LS, Barrio-Amorós CL, Cruz CAG, Wheeler WC. 2010. The phylogenetic

305 relationships of the charismatic poster frogs, Phyllomedusinae (Anura, Hylidae). Cladistics 25:

$306 \quad 1-35$

307 Frost DR. 2016. Amphibian Species of the World: an online reference. Version 6.0. Available at

308 http://research.amnh.org/herpetology/amphibia/index.html (accessed 27 May 2016)

309 Gomez-Mestre I, Wiens JJ, Warkentin KM. 2008. Evolution of adaptive plasticity: risk-sensitive

310 hatching in neotropical leaf-breeding treefrogs. Ecological Monographs 78: 205-224

311 Gomez-Mestre I, Pyron RA, Wiens JJ. 2012. Phylogenetic analyses reveal unexpected patterns in

312 the evolution of reproductive modes in frogs. Evolution 66: 3687-3700

313 Gomez-Mestre I, Warkentin KM. 2007. To hatch and hatch not: similar selective trade-offs but

314 different responses to egg predators in two closely related, syntopic treefrogs. Oecologia 153:

$315 \quad 197-206$

316 Hulme M, Viner D. 1998. A climate change scenario for the tropics. Climatic Change 39: 145-

317176

318 Kam YC, Yen CF, Hsu CL. 1998a. Water balance, growth, development, and survival of

319 arboreal frog eggs (Chirixalus eiffingeri, Rhacophoridae) importance of egg distribution in

320 bamboo stumps. Physiological Zoology 71: 534-540 
321 Kam YC, Lin CF, Lin YS, Tsal YF. 1998b. Density effects of oophagous tadpoles of Chirixalus

322 eiffingeri (Anura: Rhacophoridae): importance of maternal brood care. Herpetologica 54: 425-

$323 \quad 433$

324 Martin KL, Carter AL. 2013. Brave new propagules: terrestrial embryos in anamniotic eggs.

325 Integrative and Comparative Biology. 53: 233-247

326 Mitchell NJ. 2002. Low tolerance of embryonic desiccation in the terrestrial nesting frog

327 Bryobatrachus nimbus (Anura: Myobatrachinae). Copeia 2002: 364-373

328 Pyburn WF. 1970. Breeding behavior of the leaf-frogs Phyllomedusa callidryas and

329 Phyllomedusa dacnicolor in Mexico. Copeia 1970: 209-218

330 Pyburn WF. 1980. The function of eggless capsules and leaf in nests of the frog Phyllomedusa

331 hypochondrialis (Anura: Hylidae). Proceedings of the Biological Society of Washington 93:153332167

333 Salthe, SN. 1965. Increase in volume of the perivitelline chamber during development of Rana

334 pipiens Schreber. Physiological Zoology 38: 80-98

335 Seymour RS, Geiser F, Bradford DF. 1991a. Gas conductance of the jelly capsule of terrestrial

336 frog eggs correlates with embryonic stage, not metabolic demand or ambient $\mathrm{PO}_{2}$. Physiological

337 Zoology 64: 673-687

338 Seymour RS, Geiser F, Bradford DF. 1991b. Metabolic cost of development in terrestrial frog

339 eggs (Pseudophryne bibronii). Physiological Zoology 64: 688-696

340 Taigen TL, Pough FH, Stewart MM. 1984. Water balance of terrestrial anuran

341 (Eleutherodactylus coqui) eggs: importance of parental care. Ecology 65: 248-255

342 Touchon JC. 2012. A treefrog with reproductive mode plasticity reveals a changing balance of

343 selection for nonaquatic egg laying. The American Naturalist 180: 733-743 
344 Touchon JC, Warkentin KM. 2008. Reproductive mode plasticity: aquatic and terrestrial

345 oviposition in a treefrog. Proceedings of the National Academy of Sciences of the United States

346 of America 105: 7495-7499

347 Touchon JC, Warkentin KM. 2009. Negative synergism of rainfall patterns and predators affects

348 frog egg survival. The Journal of Animal Ecology 78: 715-723

349 Touchon JC, Warkentin KM. 2010. Short- and long- term effects of the abiotic egg environment

350 on viability, development and vulnerability to predators of a Neotropical anuran. Functional

351 Ecology 24: 566-575

352 Touchon, J. C., J. Urbina, and K. M. Warkentin. 2011. Habitat-specific constraints on induced

353 hatching in a treefrog with reproductive mode plasticity. Behavioral Ecology 22: 169-175

354 Warkentin KM. 1995. Adaptive plasticity in hatching age: a response to predation risk trade-offs.

355 Proceedings of the National Academy of Sciences of the United States of America 92: 3507-

3563510.

357 Warkentin KM. 1999. The development of behavioral defenses: a mechanistic analysis of

358 vulnerability in red-eyed tree frog hatchlings. Behavioral Ecology 10: 251-262.

359 Warkentin KM. 2000. Wasp predation and wasp-induced hatching of red-eyed treefrog eggs.

360 Animal Behaviour 60: 503-510.

361 Warkentin KM. 2002. Hatching timing, oxygen availability, and external gill regression in the

362 treefrog, Agalychnis callidryas. Physiological and Biochemical Zoology 75: 155-164.

363 Warkentin KM. 2005. How do embryos assess risk? Vibrational cues in predator induced

364 hatching of red-eyed treefrogs. Animal Behaviour 70: 59-71.

365 Warkentin KM. 2011a. Environmentally cued hatching across taxa: embryos respond to risk and

366 opportunity. Integrative and Comparative Biology 51: 14-25. 
367 Warkentin KM. 2011b. Plasticity of hatching in amphibians: evolution, trade-offs, cues and

368 mechanisms. Integrative and Comparative Biology 51:111-127.

369 Warkentin KM, Currie CC, Rehner SA. 2001. Egg-killing fungus induces early hatching of red-

370 eyed treefrog eggs. Ecology 82: 2860-2869.

371 Warkentin KM, Gomez-Mestre I, McDaniel JG. 2005. Development, surface exposure, and

372 embryo behavior affect oxygen levels in eggs of the red-eyed treefrog, Agalychnis callidryas.

373 Physiological and Biochemical Zoology 78:956-66.

374 Warkentin KM, Caldwell MS, Siok TD, D'Amato AT, McDaniel JG. 2007. Flexible information

375 sampling in vibrational assessment of predation risk by red-eyed treefrog embryos. The Journal 376 of Experimental Biology. 210: 614-619.

377

378

379

380

381 


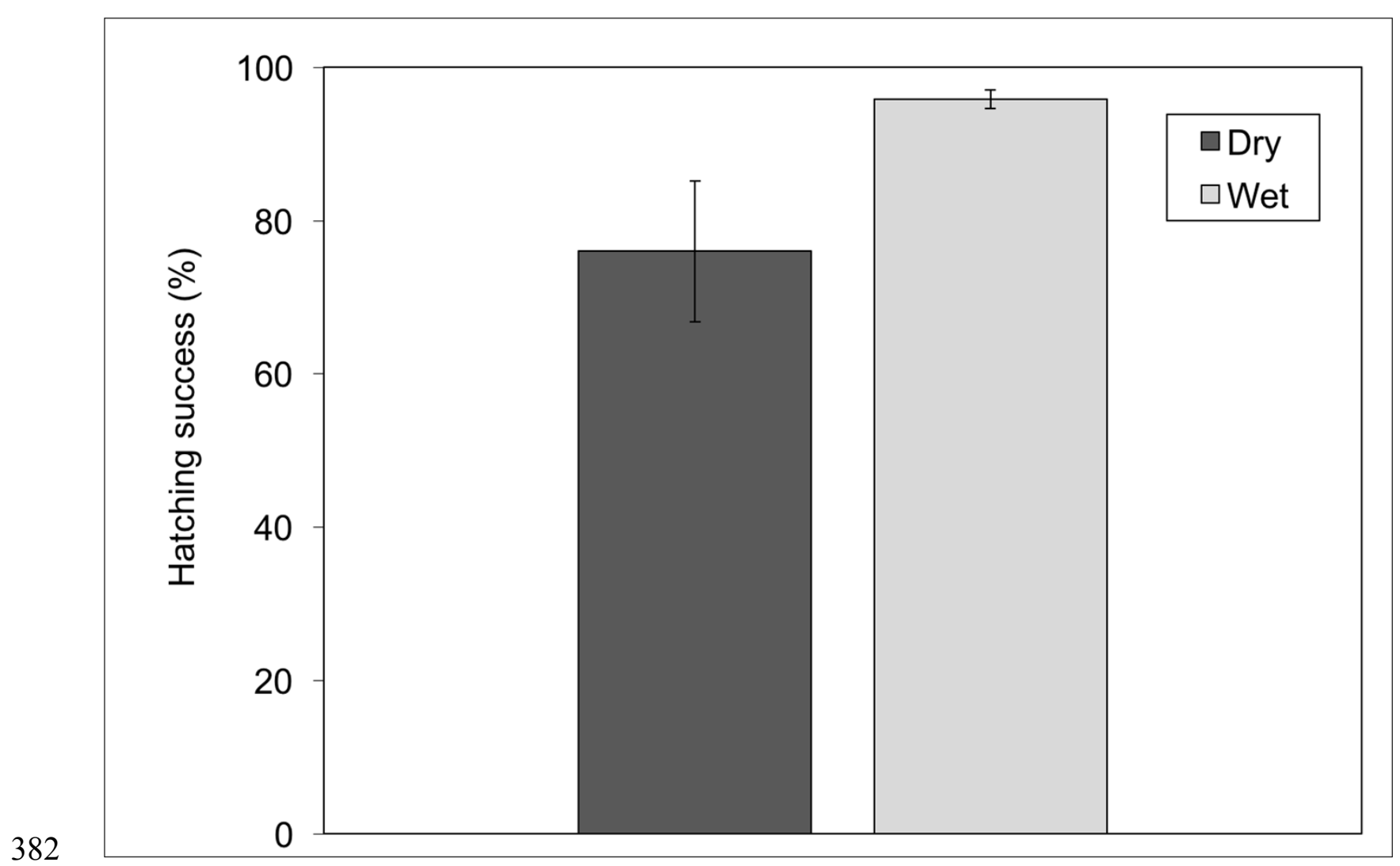

383 FIGURE 1. Hatching success of well-hydrated Agalychnis callidryas embryos was significantly

384 higher than that of drying embryos. Data are mean percent of embryos that hatched successfully 385 ( \pm SE across 15 clutches per treatment). 


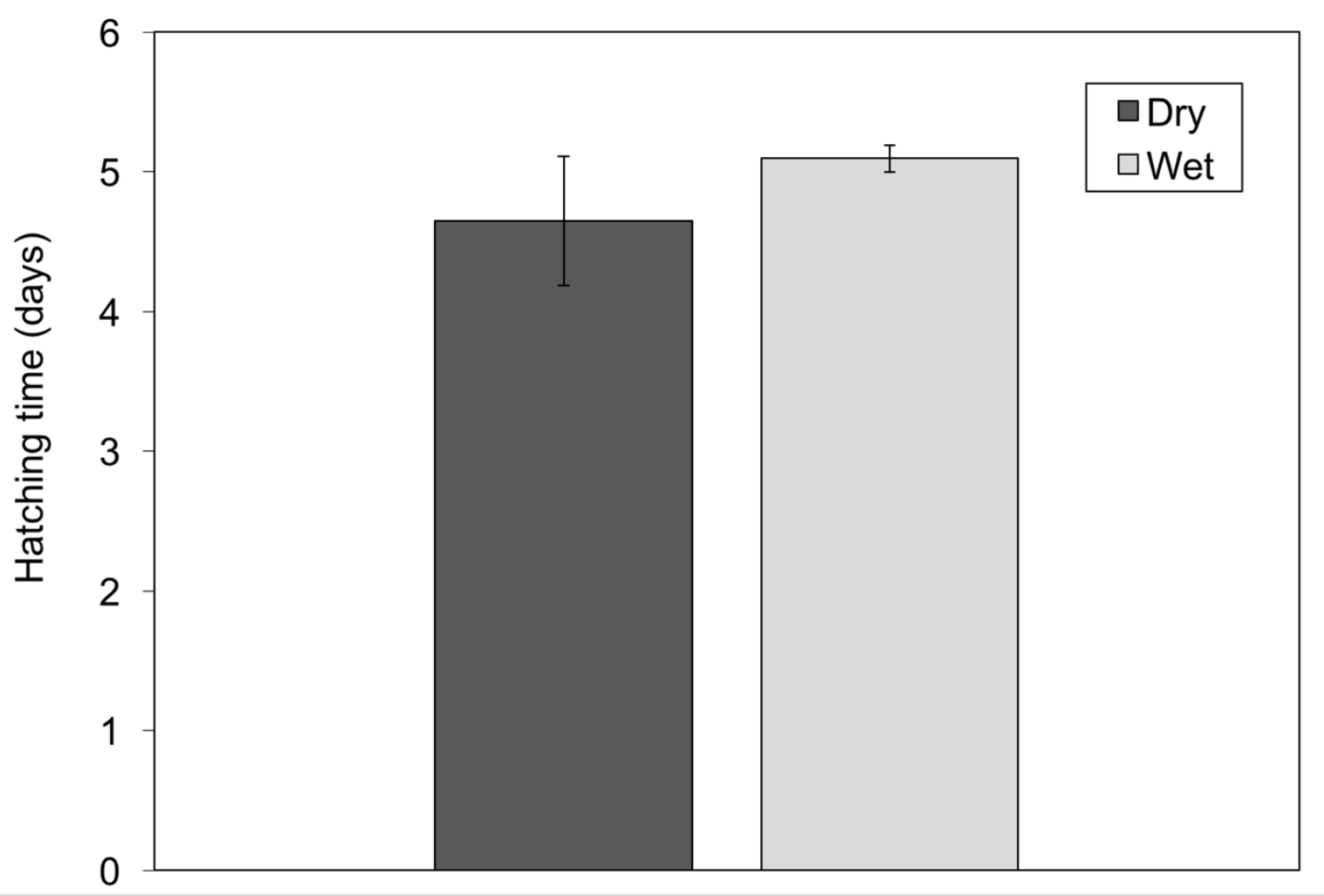

387 FIGURE 2. Agalychnis callidryas embryos in dry clutches hatched earlier than did those in wet

388 clutches. Data shown are the mean age when clutches started hatching, \pm SE across 15 clutches 389 per treatment.

390

391 


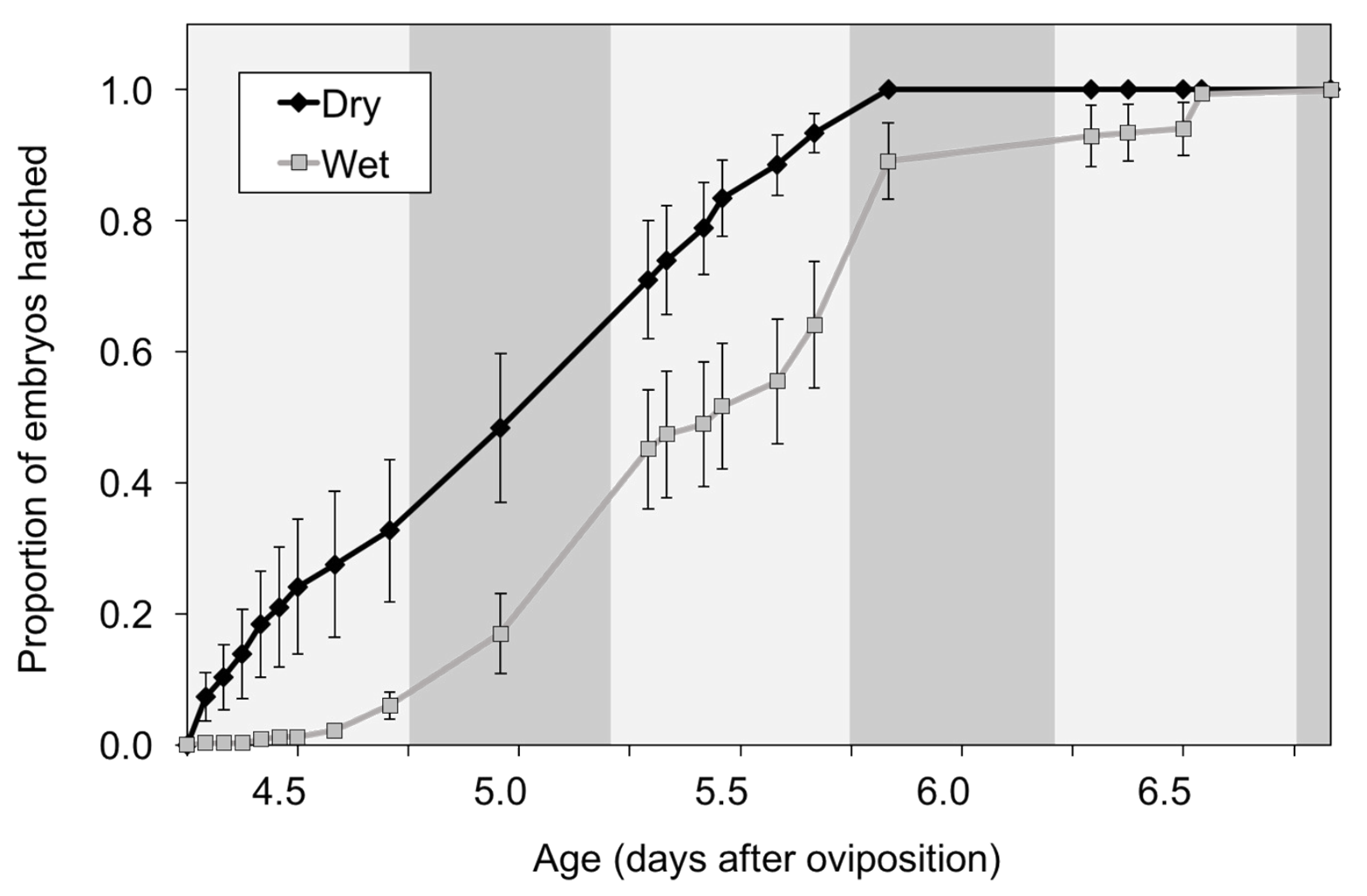

393 FIGURE 3. Agalychnis callidryas embryos hatched $\approx 11 \%$ earlier from drying vs. wet clutches.

394 Data are mean proportion hatched at each age ( \pm SE across 15 clutches per treatment), of all that 395 eventually hatched. Dark and light shading along the x-axis indicates photoperiod. 


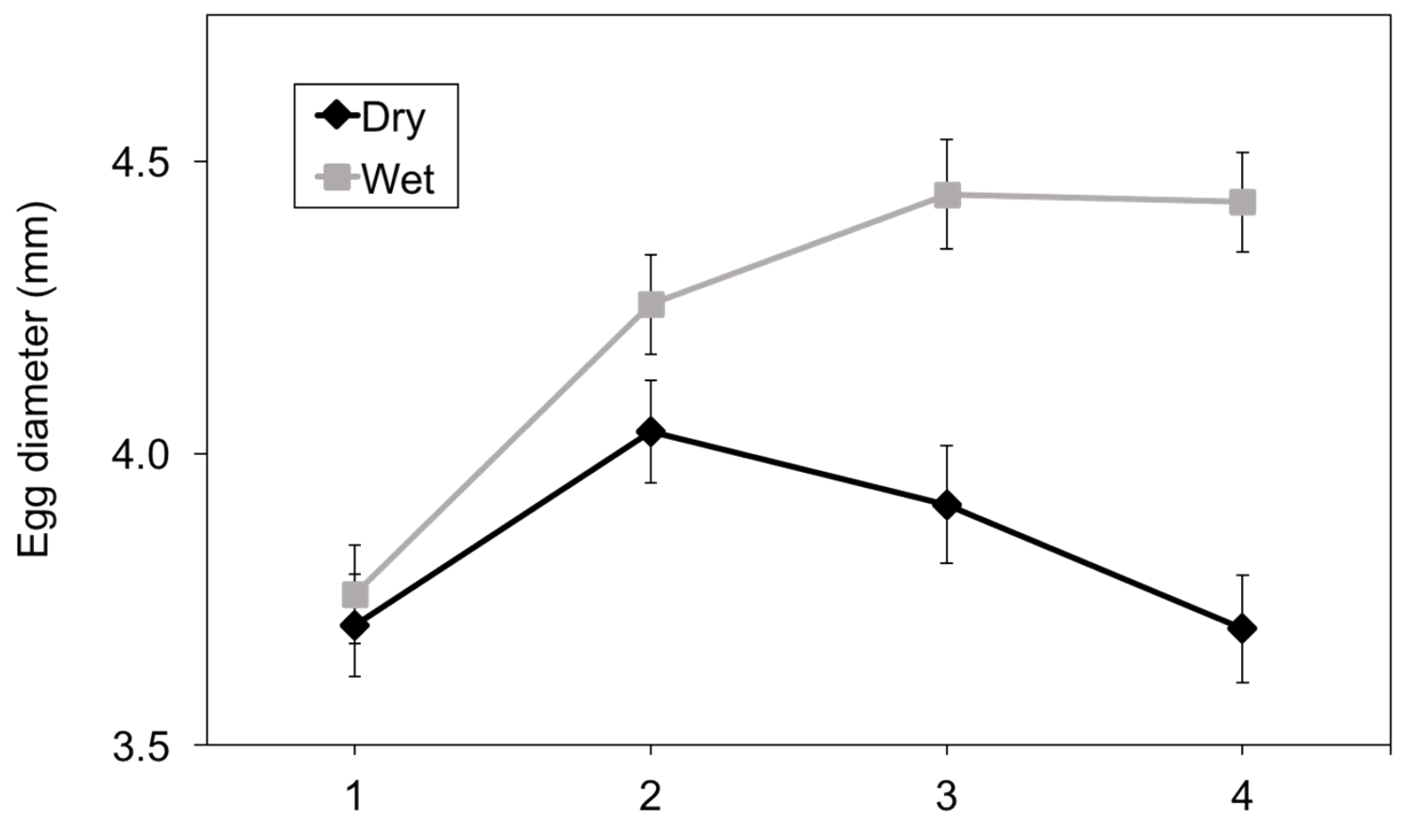

Age (days after oviposition)

FIGURE 4. Effect of development and hydration treatment on Agalychnis callidryas egg the interaction between hydration treatment and age. 


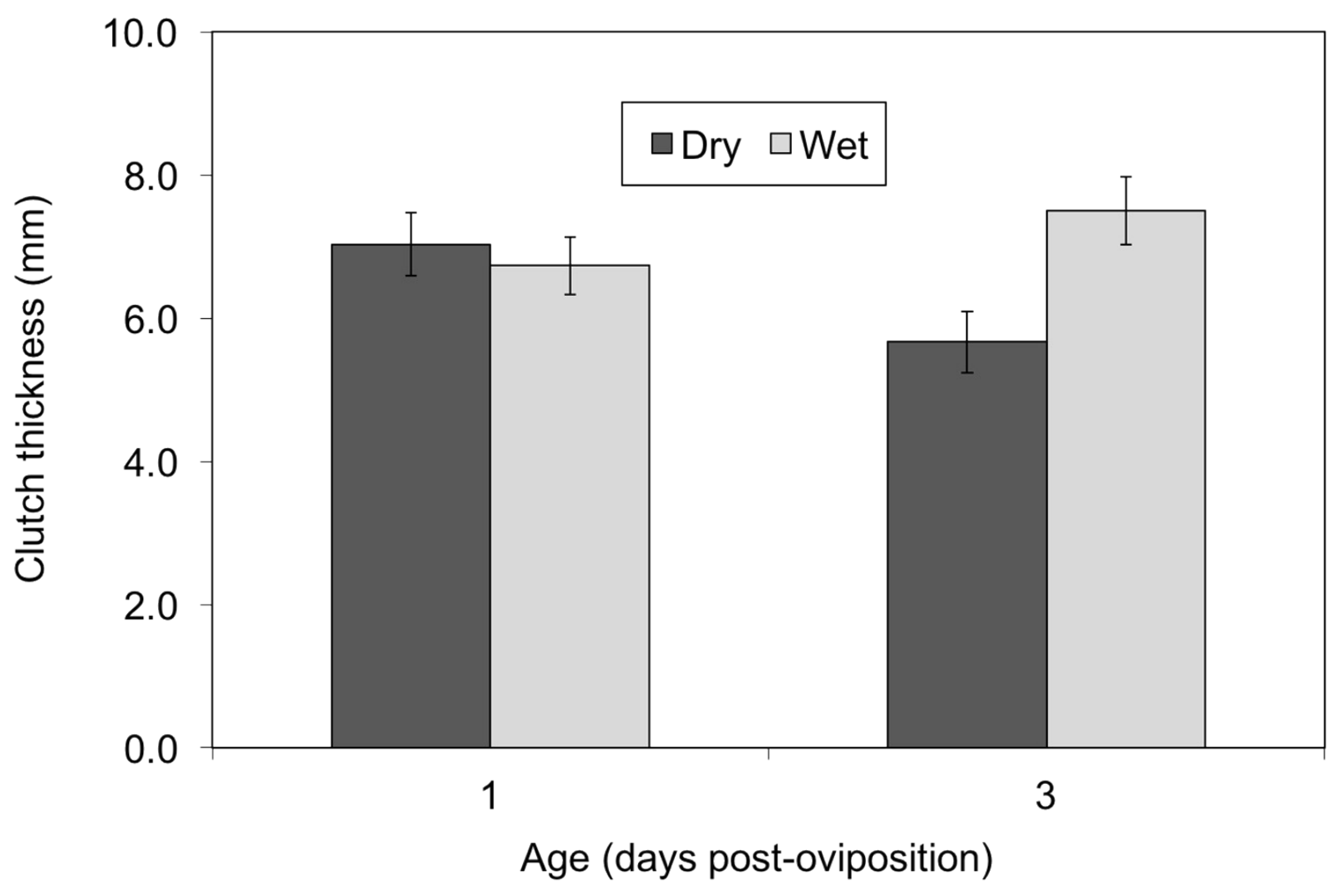

403 FIGURE 5. Thickness of Agalychnis callidryas egg clutches before (age $1 \mathrm{~d}$ ) and 2 days after

404 (age $3 \mathrm{~d}$ ) the imposition of different hydration treatments. Data are means \pm SE across 15

405 clutches per treatment. Mean clutch thickness was a function of the interaction between

406 hydration treatment and age,

407 